\title{
ISOMERISASI EUGENOL MENJADI ISOEUGENOL DENGAN METODE SONIKASI
}

\section{(ISOMERISATION OF EUGENOL TO ISOEUGENOL USING SONICATION METHOD)}

\author{
Arief Riyanto, Retno Yunilawati, Dwinna Rahmi, Novi Nur Aidha, \\ dan Emmy Ratnawati \\ Balai Besar Kimia dan Kemasan, Kementerian Perindustrian \\ JI. Balai Kimia No.1 Pekayon, Pasar Rebo, Jakarta Timur \\ E-mail : peranthus@gmail.com
}

Received : 4 Februari 2015; revised : 25 Februari 2015; accepted : 4 Maret 2015

\begin{abstract}
ABSTRAK
Isoeugenol merupakan senyawa turunan eugenol yang banyak digunakan di industri farmasi, kosmetik, perisa makanan dan minuman. Konversi eugenol menjadi isoeugenol dilakukan melalui reaksi isomerisasi. Isomerisasi eugenol dapat dilakukan secara konvensional dengan pemanasan pada suhu tinggi, namun tidak efisien sehingga dilakukan dengan metode pemanfaatan gelombang mikro yang memerlukan energi cukup besar. Pada penelitian ini dilakukan isomerisasi dengan memanfaatkan gelombang ultrasonik agar dihasilkan metode yang lebih efisien. Isomerisasi berjalan optimal pada kondisi amplitudo $70 \%$ dan 40 menit, menggunakan pelarut etanol, dan dengan perbandingan berat katalis $\mathrm{RhCl}_{3}$ terhadap eugenol sebesar $1: 2000$. Pada kondisi tersebut dihasilkan isoeugenol total hampir $100 \%$ dengan komposisi cis isoeugenol sekitar $8,23 \%$ dan trans isoeugenol sekitar $91,76 \%$.
\end{abstract}

Kata kunci : Eugenol, Isoeugenol, Katalis $\mathrm{RhCl}_{3}$

\section{ABSTRACTS}

Isoeugenol is an eugenol derivatives are widely used in the pharmaceutical industries, cosmetics, food and beverage flavor. Conversion of eugenol to isoeugenol made through isomerization reaction. Eugenol isomerization can be done conventionally by heating at high temperature and method use micro wave which required large of energy. In this research, the isomerization is done by using ultrasonic waves in order to produce more efficient method. Isomerization optimal at $70 \%$ amplitude condition, within 40 minutes, use ethanol, and the weight ratio of the catalyst RhCl3 eugenol of $1: 2000$. In these conditions produced nearly $100 \%$ isoeugenol in total with the composition of $8.23 \%$ isoeugenol cis and trans approximately $91.76 \%$.

Keywords : Eugenol, Isoeugenol, $\mathrm{RhCl}_{3}$ catalyst

\section{PENDAHULUAN}

Indonesia memiliki luas areal tanaman cengkeh terluas di dunia, yaitu sekitar 241.800 ha atau lebih dari $70 \%$ luas areal tanaman cengkeh di dunia. Sentra produksi minyak cengkeh terdapat di Jawa Tengah, Jawa Barat, Jawa Timur, Sumatra Barat, Bali, dan Sulawesi Selatan. Produksi minyak cengkeh Indonesia pada tahun 2007 sekitar 2.500 ton dengan perkiraan pemakaian dunia sekitar 3.500 ton / tahun. Minyak cengkeh terdiri dari beberapa komponen yaitu eugenol, metil eugenol, eugenol asetat, dan caryophylene (Priyosetyoko et al. 2014). Komponen terbesar
( $80 \%$ berat sampai $90 \%$ berat) minyak cengkeh adalah eugenol atau 3-(4-hidroksi-3-metoksifenil) propena. Pada eugenol terdapat gugus-gugus fungsi yang dapat diubah secara kimia, pada prinsipnya eugenol merupakan bahan awal yang sangat berguna bagi sintesis senyawa-senyawa yang lebih bermanfaat. Salah satu turunan dari eugenol adalah senyawa isoeugenol, yang merupakan bahan dasar dalam industri farmasi, kosmetika, serta industri perisa untuk makanan dan minuman. 
Prinsip transformasi eugenol menjadi isoeugenol adalah reaksi isomerisasi, dimana ikatan rangkap pada gugus alkenil pindah ke posisi konyugasi dengan ikatan rangkap pada cincin benzena eugenol (Sharma et al. 2006). Isomerisasi eugenol menjadi isoeugenol merupakan reaksi katalitik yang membutuhkan panas dan katalis, baik katalis basa dan katalis logam transisi. Reaksi isomerisasi eugenol menjadi isoeugenol ditunjukkan pada Gambar 1. Reaksi isomerisasi eugenol menjadi isoeugenol secara konvensional, menggunakan katalis basa kuat pada suhu yang tinggi dan waktu yang lama. Metode ini tidak efisien sehingga kemudian berkembang metode menggunakan pemanasan gelombang mikro (microwave). Dengan metode panas gelombang mikro dapat mempercepat waktu reaksi isomerisasi hingga beberapa kali (Mulyono dan Hidayat 2006; Setyarini 2010). Namun metode pemanasan gelombang mikro ini membutuhkan energi yang tinggi sehingga apabila diterapkan pada skala besar belum efisien. Oleh karena itu, perlu dicari metode lain yang lebih efisien. Salah satu metode yang belum dilakukan adalah metode sonikasi, yaitu metode yang memanfaatkan energi gelombang ultrasonik.

Sonikasi merupakan aplikasi dari penggunaan energi gelombang ultrasonik (energi suara) untuk berbagai aplikasi. Beberapa pemanfaatan ultrasonik pada industri antara lain adalah thermoplastic welding, ekstraksi, kristalisasi, floatasi, pengeringan, degassing, defoaming, cutting, drilling, soldering, filtrasi, homogenisasi (pengadukan atau pencampuran), desolusi, dan deagregasi serbuk. Sonikasi berarti memberi perlakuan ultrasonik pada suatu bahan dengan kondisi tertentu, sehingga bahan tersebut mengalami reaksi kimia akibat perlakuan tersebut (Ingole and Khedkar 2012). Proses sonikasi dilakukan dengan cara menggunakan gelombang ultrasonik dengan rentang frekuensi $20 \mathrm{kHz}$ sampai $10 \mathrm{MHz}$ ke dalam medium. Energi yang diberikan gelombang ultrasonik akan menggetarkan partikel dalam medium hingga bisa memecah ikatan antar molekul (Roshana et al. 2011). Getaran yang ditimbulkan oleh energi gelombang ultrasonik diharapkan akan dapat memindahkan ikatan rangkap pada gugus alkenil pindah ke posisi konyugasi dengan ikatan rangkap pada cincin benzena eugenol sehingga eugenol terkonversi menjadi isoeugenol.

\section{BAHAN DAN METODE}

\section{Bahan}

Bahan-bahan yang digunakan dalam penelitian ini antara lain eugenol (PT. Indesso Aroma), etanol teknis, katalis $\mathrm{RhCl}_{3}$, metanol (grade kromatografi), dan standar isoeugenol (PT.Indesso Aroma).

Peralatan yang digunakan terdiri dari sonikator (QSonica Sonicators/QSS), peralatan gelas yang biasa digunakan di laboratorium, refraktometer, dan Gas Chromatography Spectrophotometer Massa (GCMS) Agilent 6890.

\section{Metode}

Eugenol sebagai bahan baku terlebih dahulu dianalisis untuk mengetahui sifat fisis dan komposisi senyawa kimia yang ada di dalamnya. Analisis yang dilakukan meliputi bobot jenis, indeks bias, kelarutan dalam alkohol, dan komposisi senyawa kimia. Setelah itu dilakukan proses konversi menggunakan sonikasi dengan melihat pengaruh pelarut, perbandingan jumlah katalis, amplitudo, dan waktu sonikasi. Kondisi pada proses sonikasi ditentukan dari percobaan pendahuluan yang telah dilakukan sebelumnya.

\section{Pengaruh Pelarut}

Pelarut yang digunakan dalam penelitian ini adalah etanol. Eugenol sebanyak $25 \mathrm{~g}$ ditambahkan katalis $\mathrm{RhCl}_{3}$ dengan perbandingan berat katalis $\mathrm{RhCl}_{3}$ : eugenol = $1: 2000$ tanpa pelarut. Di tempat lain disiapkan pula eugenol sebanyak $25 \mathrm{~g}$ ditambahkan katalis $\mathrm{RhCl}_{3}$ yang telah dilarutkan dalam etanol dengan perbandingan berat katalis $\mathrm{RhCl}_{3}$ : eugenol $=1: 2000$. Kemudian dilakukan sonikasi pada amplitudo 50 selama 20 menit. Hasil reaksi yang diperoleh selanjutnya dianalisis menggunakan GCMS untuk mengetahui komposisinya.

\section{Pengaruh Jumlah Katalis}

Eugenol sebanyak $25 \mathrm{~g}$ ditambahkan katalis $\mathrm{RhCl}_{3}$ yang telah dilarutkan dalam etanol dengan perbandingan berat katalis $\mathrm{RhCl}_{3}$ : eugenol = $1: 2000$.

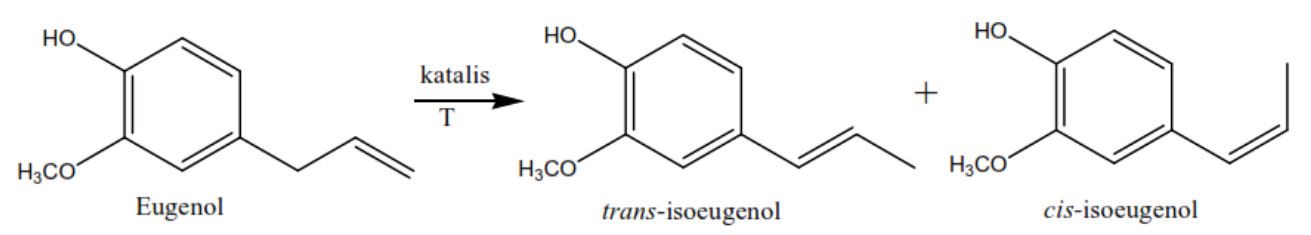

Gambar 1. Reaksi isomerisasi eugenol menjadi isoeugenol 
Di tempat lain disiapkan pula eugenol sebanyak $25 \mathrm{~g}$ ditambahkan katalis $\mathrm{RhCl}_{3}$ yang telah dilarutkan dalam etanol dengan perbandingan berat katalis $\mathrm{RhCl}_{3}$ : eugenol = $1: 3000$. Kemudian dilakukan sonikasi pada amplitudo 70 dengan beberapa variasi waktu (5 menit, 10 menit, 20 menit, dan 40 menit). Hasil reaksi yang diperoleh selanjutnya dianalisis menggunakan GCMS untuk mengetahui komposisinya.

\section{Pengaruh Amplitudo Dan Waktu Sonikasi}

Eugenol sebanyak $25 \mathrm{~g}$ ditambahkan katalis $\mathrm{Rh}$ yang telah dilarutkan dalam etanol dengan perbandingan berat katalis $\mathrm{RhCl}_{3}$ : eugenol = $1: 2000$. Kemudian dilakukan sonikasi pada amplitudo 50 dan 70 dengan beberapa variasi waktu (5 menit, 10 menit, 20 menit, dan 40 menit). Hasil reaksi yang diperoleh selanjutnya dianalisis menggunakan GCMS untuk mengetahui komposisinya.

\section{HASIL DAN PEMBAHASAN}

\section{Analisis Bahan Baku (Eugenol)}

Hasil analisis sifat fisis eugenol yang digunakan untuk penelitian (dari PT. Indesso
Aroma) dapat dilihat pada Tabel 1. Spesifikas eugenol yang diperdagangkan di Indonesia sampai saat ini belum diatur oleh Standar Nasional Indonesia (SNI), sehingga produsen memproduksi sesuai kemampuan masing-masing dan umumnya disesuaikan dengan spesifikasi permintaan pembeli. Hasil analisis menggunakan GCMS menunjukkan bahwa senyawa eugenol memiliki puncak pada waktu retensi 22,3 menit (Gambar 2).

\section{Konversi Eugenol Menjadi Isoeugenol}

Proses pembuatan isoeugenol merupakan reaksi isomerisasi yang sebenarnya hanya menggeser posisi ikatan rangkap pada grup alkenil ke posisi konjugasi pada cincin benzena (Sharma et al. 2006). Pergeseran ikatan rangkap pada reaksi isomerisasi dapat dilihat pada Gambar 3. Dilihat struktur eugenol dan isoeugenol pada Gambar 3, eugenol lebih polar daripada isoeugenol, hal ini dikarenakan adanya ikatan rangkap gugus propenil yang tidak terkonjugasi pada struktur eugenol. Isoeugenol bersifat kurang polar, karena ikatan rangkap pada gugus propenilnya terkonjugasi dengan benzena.

Tabel 1. Hasil analisis sifat-sifat fisis eugenol (PT. Indesso)

\begin{tabular}{clcl}
\hline No & \multicolumn{1}{c}{ Karakteristik } & Hasil pengujian & \multicolumn{1}{c}{ Metode pengujian } \\
\hline 1 & Bobot Jenis $20^{\circ} \mathrm{C} / 20^{\circ} \mathrm{C}$ & 1,07 & SNI 06-2387-2006 \\
2 & Indeks bias $\left({ }^{\mathrm{n}} \mathrm{D}_{20}\right)$ & 1,54 & SNI 06-2387-2006 \\
3 & Kadar Air $(\% \mathrm{~b} / \mathrm{b})$ & 0,01 & ASTM D-95 \\
4 & Kelarutan dalam etanol & $1: 1$ jernih & SNI 06-2387-2006 \\
& $70 \%$ pada suhu $20^{\circ} \mathrm{C}$ & seterusnya jernih & \\
\hline
\end{tabular}

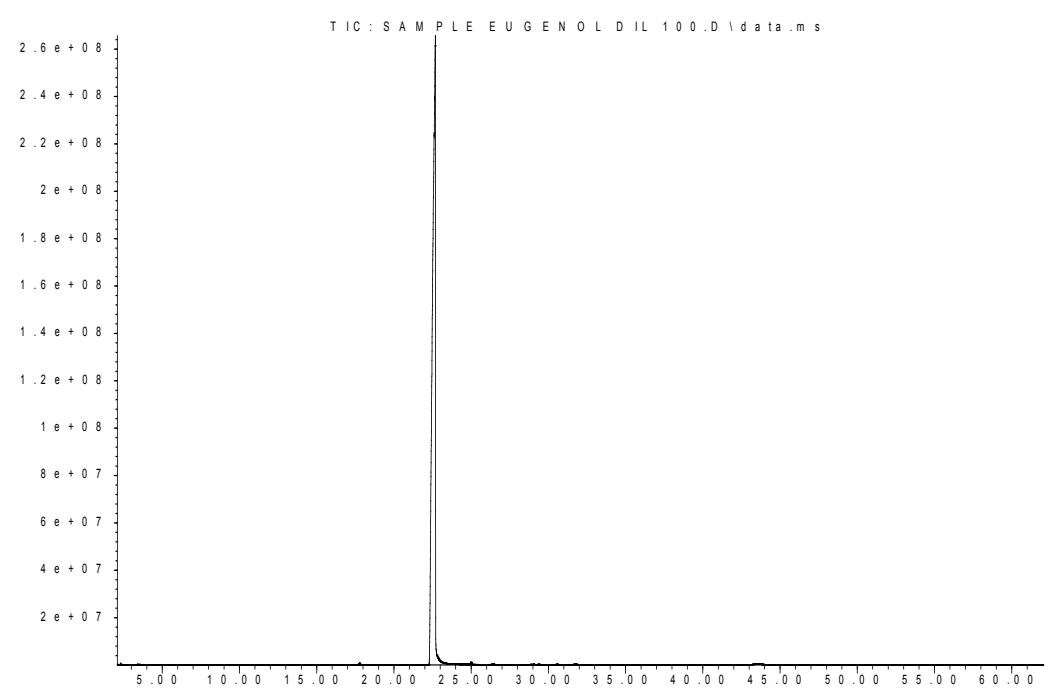

Gambar 2. Kromatogram eugenol (PT. Indesso Aroma) yang dianalisis menggunakan GCMS 


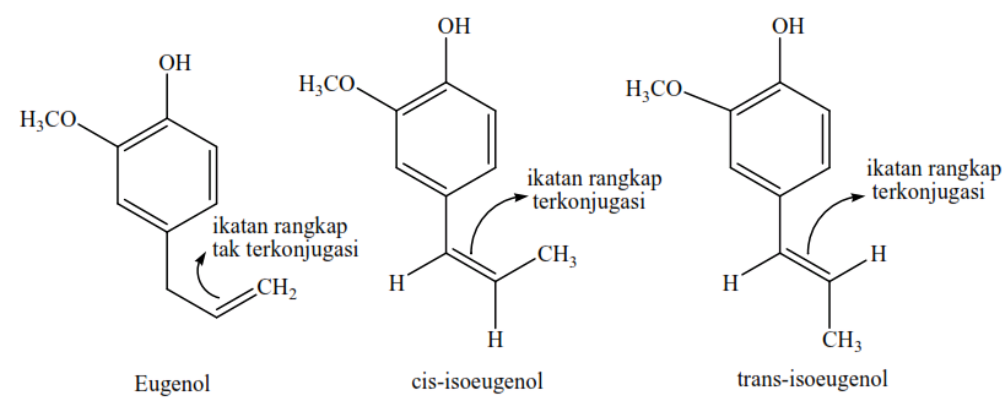

Gambar 3. Pergeseran ikatan rangkap eugenol, cis-isoeugenol, dan trans-isoeugenol

Isomerisasi eugenol menjadi isoeugenol tingkat komersial dilakukan dengan cara mereaksikan dengan basa kuat seperti $\mathrm{KOH}$ dan $\mathrm{NaOH}$ sebagai katalis (Kadarrohman 1994) dapat juga menggunakan katalis hidrostalsit seperti $\mathrm{Mg}$, Al yang merupakan katalis padat bersifat basa (Kishore and Kannan 2002). Reaksi isomerisasi umumnya dilakukan pada suhu tinggi $\left(140{ }^{\circ} \mathrm{C}\right.$ sampai $\left.190{ }^{\circ} \mathrm{C}\right)$ dan waktu reaksi yang lama yaitu 5 jam sampai 7 jam. Penggunaan katalis $\mathrm{KOH}$ untuk isomerisasi eugenol telah dilakukan Kadarohman (1999) dan didapatkan total isoeugenol sebesar $93,71 \%$.

Penggunaan teknologi gelombang mikro dapat mempersingkat waktu secara signifikan. Hasil penelitian Mulyono dan Hidayat (2006) menunjukkan waktu reaksi isomerisasi hanya memerlukan waktu 15 menit sampai 20 menit yaitu 15 kali sampai 20 kali lebih cepat dari pemanasan konvensional dan Soesanto (2006) menggunakan gelombang mikro dengan katalis rhodium menghasilkan total konversi mencapai 95,3\%. Penggunaan energi gelombang ultrasonik untuk isomerisasi eugenol dalam penelitian ini dapat meningkatkan hasil konversi. Isomerisasi dilakukan menggunakan katalis rhodium dalam bentuk $\mathrm{RhCl}_{3}$, dengan variabel pelarut, jumlah katalis, amplitudo, dan waktu. Isoeugenol yang terbentuk dianalisis menggunakan GCMS dengan isoeugenol dari PT.Indesso Aroma digunakan sebagai pembanding. Hasil analisis isoeugenol PT. Indesso Aroma menggunakan GCMS dapat dilihat pada Gambar 4 yang memperlihatkan cis isoeugenol pada waktu retensi 24,5 menit dan trans isoeugenol pada waktu retensi 26,3 menit.

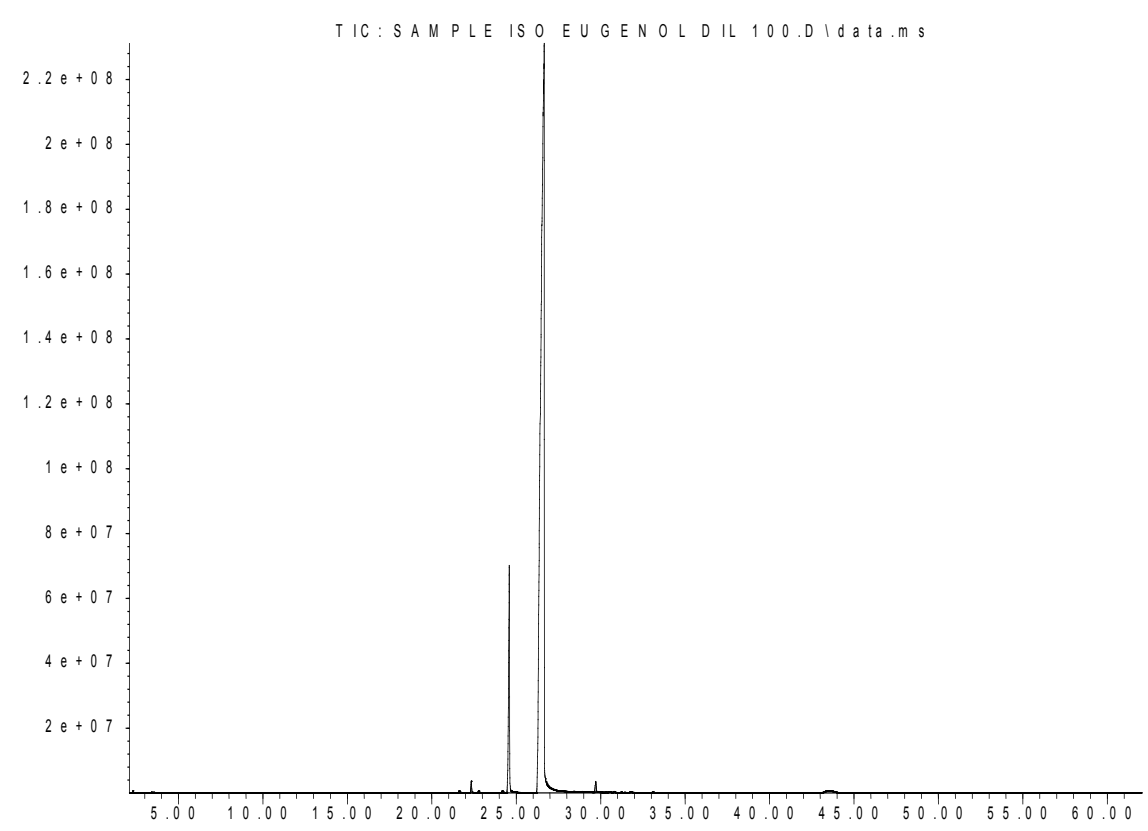

Gambar 4. Kromatogram isoeugenol PT Indesso (pembanding) yang dianalisis menggunakan GCMS 


\section{Pengaruh Pelarut Terhadap Isomerisasi}

Pada penelitian ini sebagai pelarut digunakan etanol dengan pertimbangan etanol akan mudah menguap selama proses sonikasi. Penggunaan pelarut etanol juga pernah dilakukan untuk isomerisasi eugenol menggunakan gelombang mikro dengan katalis rhodium (Hidayat et al. 2007 ). Untuk melihat pengaruh pelarut etanol ini, dilakukan analisis reaktan (eugenol) dan hasil reaksi (isoeugenol) seperti ditampilkan pada Tabel 2. Sonikasi dilakukan pada amplitudo $50 \%$ dengan waktu reaksi 20 menit.

Dari Tabel 2. terlihat bahwa penggunaan pelarut secara signifikan mempengaruhi hasil isoeugenol. Pelarut berfungsi untuk melarutkan katalis $\mathrm{RhCl}_{3}$ sehingga bidang kontak antara reaktan dengan katalis menjadi semakin besar. Selain itu karena sifat eugenol yang viskositasnya relatif besar sehingga efek pelarut juga akan menurunkan viskositas dari eugenol.

Semakin kecil viskositasnya maka kontak antara reaktan dengan katalis semakin besar. Berdasarkan persamaan Arhenius yaitu konstanta kecepatan reaksi, dimana dipengaruhi oleh faktor suhu, frekuensi tumbukan, dan energi aktivasi. Dalam hal ini, pelarut berfungsi untuk meningkatkan frekuensi tumbukan. Persamaan Arhenius dapat dilihat pada persamaan dibawah ini :

$$
K=A e^{\frac{E a}{R T}}
$$

$\mathrm{K}=$ konstanta

$A=$ Faktor frekuensi

Ea=energi aktivasi

$\mathrm{R}=$ konstanta konstanta gas (8 $314 \mathrm{~J} / \mathrm{K}$ gas $(8.314 \mathrm{~J} / \mathrm{K}-\mathrm{mol})$

$\mathrm{T}=$ Suhu

Persamaan tersebut dalam bentuk logaritma dapat ditulis :

$$
\begin{aligned}
& \ln K=\ln A-\left(\frac{E a}{R T}\right) \\
& \ln K=-\frac{E a}{R T} x \frac{1}{T}+\ln A
\end{aligned}
$$

\section{Pengaruh Jumlah Katalis}

Hasil reaksi isomerisasi eugenol pada perbandingan katalis yang berbeda ditampilkan pada Tabel 3. Perbandingan yang digunakan adalah perbandingan berat. Satu bagian (berat) katalis berbanding dengan 2000 bagian (berat) eugenol.

Pada penelitian Soesanto (2006), ratio katalis yang digunakan pada kisaran 1:400 hingga 1:1250. Dalam penelitian ini,

Tabel 2. Hasil konversi isomerisasi menggunakan katalis $\mathrm{RhCl}_{3}$ tanpa pelarut dan dengan pelarut.

\begin{tabular}{ccccc}
\hline Pelarut & Eugenol & \multicolumn{3}{c}{ Isoeugenol (\%) } \\
\cline { 3 - 5 } & sisa $(\%)$ & Cis & Trans & Isoeugenol total \\
\hline Tanpa pelarut & 71,68 & 5,85 & 22,46 & 28,31 \\
Etanol & 32,47 & 14,48 & 51,62 & 66,10 \\
\hline
\end{tabular}

Tabel 3. Hasil konversi isomerisasi metode sonikasi pada perbandingan jumlah katalis $\mathrm{RhCl}_{3}$

\begin{tabular}{ccccccc}
\hline Perbandingan katalis & $\begin{array}{c}\text { Amplitudo } \\
(\%)\end{array}$ & $\begin{array}{c}\text { Waktu } \\
\text { (menit) }\end{array}$ & $\begin{array}{c}\text { Eugenol } \\
\text { sisa }(\%)\end{array}$ & cis & $\begin{array}{c}\text { Isoeugenol (\%) } \\
\text { trans }\end{array}$ & total \\
\hline $1: 2000$ & 70 & 5 & 4,59 & 9.56 & 83.97 & 93,53 \\
& & 10 & 2,56 & 12.02 & 83.47 & 95,49 \\
& & 20 & 2,58 & 12.16 & 83.35 & 95,51 \\
$1: 3000$ & 40 & 0 & 8.24 & 91.76 & 100 \\
& \multirow{2}{*}{70} & 5 & 5,39 & 10,04 & 82,36 & 92,40 \\
& & 10 & 5,77 & 10,92 & 82,17 & 93,09 \\
& & 20 & 5,78 & 12,33 & 81,61 & 93,94 \\
& & 40 & 5,64 & 10,02 & 84.15 & 94,17 \\
\hline
\end{tabular}

Keterangan : Amplitudo A\% berarti menggunakan amplitudo sebesar $\mathrm{A} \%$ dari amplitudo maksimal yang dapat dicapai oleh alat sonikasi yang digunakan 
pada percobaan awal dengan penggunaan 1:2000 telah mendapatkan hasil yang signifikan sehingga digunakan ratio yang lebih rendah lagi pada percobaan selanjutnya $(1: 3000)$.

Pada Gambar 5. terlihat bahwa konversi eugenol yang ditandai dengan persentase isoeugenol pada penggunaan ratio katalis 1:2000 lebih tinggi dibandingkan pada ratio katalis 1:3000. Dapat dipahami bahwa semakin banyak katalis maka tumbukan yang terjadi antara molekul katalis dengan molekul eugenol lebih besar sehingga kemungkinan terjadinya isomerisasi semakin besar.

Gambar 6. memperlihatkan terjadinya peningkatan konversi eugenol menjadi isoeugenol pada penggunaan ratio katalis $1: 3000$ ke 1:2000. Pada menit ke 20, justru terjadi penurunan, namun dari tren grafik yang ada, seharusnya terjadi peningkatan. Secara umum, semakin besar jumlah katalis semakin besar pula konversi eugenol menjadi isoeugenol.

\section{Pengaruh Amplitudo Dan Waktu Sonikasi}

Hasil konversi eugenol pada beberapa variasi amplitudo dan waktu reaksi dapat dilihat pada Tabel 4. Pada amplitudo $50 \%$, waktu 5 menit, dan 10 menit tidak ada data karena terjadi kerusakan sampel yang cepat teroksidasi, sedangkan pada amplitudo $70 \%$, waktu 60 menit tidak dilakukan karena campuran suhunya sudah sangat tinggi, disebabkan karena energi gelombang ultrasonik yang menghasilkan panas dan terakumulasi dalam campuran.

Gambar 7. menunjukkan hubungan konversi eugenol dengan waktu reaksi pada amplitude $50 \%$ dan $70 \%$. Pada amplitudo $50 \%$ persentase isoeugenol dalam campuran pada waktu reaksi 20 menit pada kisaran $65 \%$ dan terus naik sampai pada menit ke 40. Dari menit ke 40 sampai dengan 60, kenaikan tidak signifikan lagi dan relatif tetap. Kemungkinan terjadi kesetimbangan reaksi sehingga komposisi senyawa dalam campuran tidak berubah, sedangkan pada amplitudo $70 \%$, konversi eugenol menjadi isoeugenol mencapai hampir $100 \%$ pada menit ke 40, dengan kromatogram hasil analisis ditampilkan pada Gambar 8. Perubahan tidak terlalu signifikan dari menit ke 5 sampai dengan menit ke 40 . Oleh karena itu jika teknologi pemisahan atau pemurnian isoeugenol tersedia akan lebih baik waktu reaksi pada 5 menit karena konversinya telah cukup tinggi.

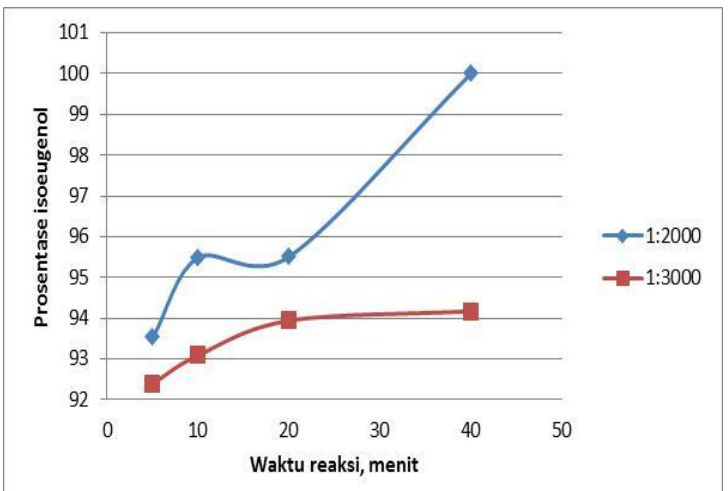

Gambar 5. Hubungan antara komposisi isoeugenol dengan waktu reaksi pada amplitudo $70 \%$ dengan variabel perbandingan katalis dengan eugenol

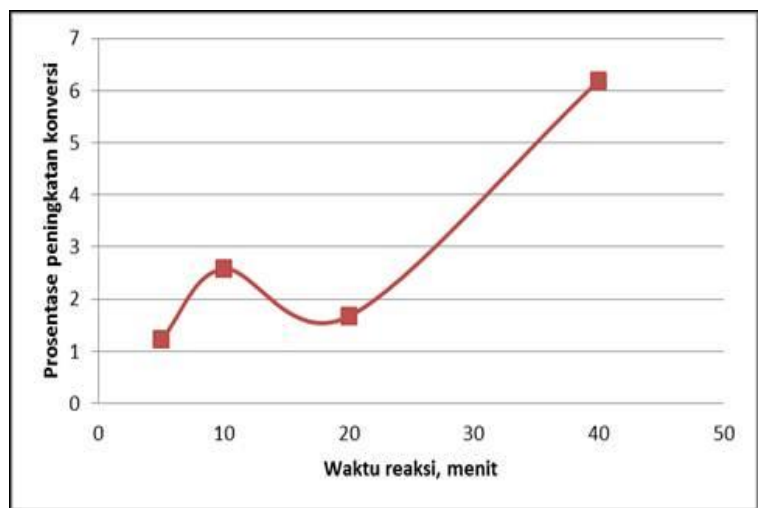

Gambar 6. Peningkatan konversi eugenol terhadap peningkatan ratio katalis $(1: 3000: 1: 2000)$ 
Tabel 4. Hasil konversi isomerisasi metode sonikasi pada beberapa variasi amplitudo dan waktu sonikasi

\begin{tabular}{cccccc}
\hline \multirow{2}{*}{ Amplitudo } & Waktu & Eugenol & \multicolumn{3}{c}{ Isoeugenol (\%) } \\
\cline { 5 - 6 } (menit) & sisa (\%) & cis-isoeugenol & $\begin{array}{c}\text { trans- } \\
\text { isoeugenol }\end{array}$ & $\begin{array}{c}\text { Isoeugenol } \\
\text { total }\end{array}$ \\
\hline 50 & 5 & - & - & - & - \\
50 & 10 & - & - & - & - \\
50 & 20 & 32,47 & 14,48 & 51,62 & 66,10 \\
50 & 40 & 4,90 & 17,25 & 74,81 & 92,06 \\
50 & 60 & 3,93 & 17,28 & 77,75 & 95,03 \\
70 & 5 & 4,59 & 9.56 & 83.97 & 93,53 \\
70 & 10 & 2,56 & 12.02 & 83.47 & 95,49 \\
70 & 20 & 2,58 & 12.16 & 83.35 & 95,51 \\
70 & 40 & 0 & 8.23 & 91.76 & 99,99 \\
\hline
\end{tabular}

Keterangan : Amplitudo $\mathrm{A} \%$ berarti menggunakan amplitudo sebesar $\mathrm{A} \%$ dari amplitudo maksimal yang dapat dicapai oleh alat sonikasi yang digunakan

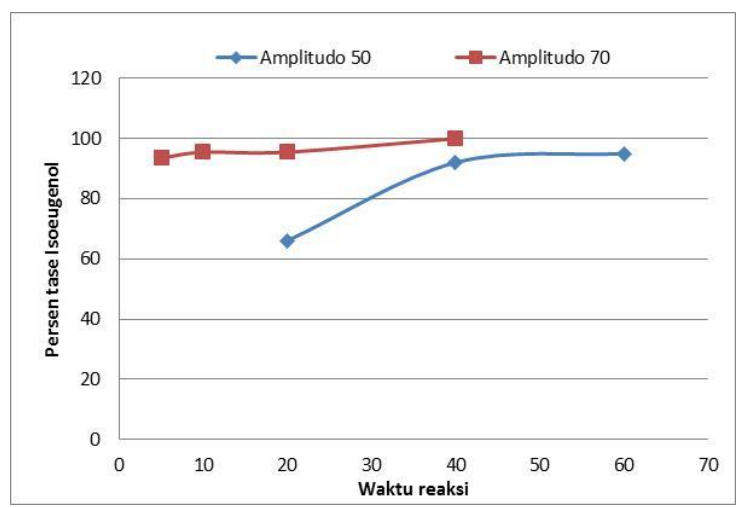

Gambar 7. Hubungan konversi eugenol dengan waktu reaksi pada amplitudo 50\% dan $70 \%$.

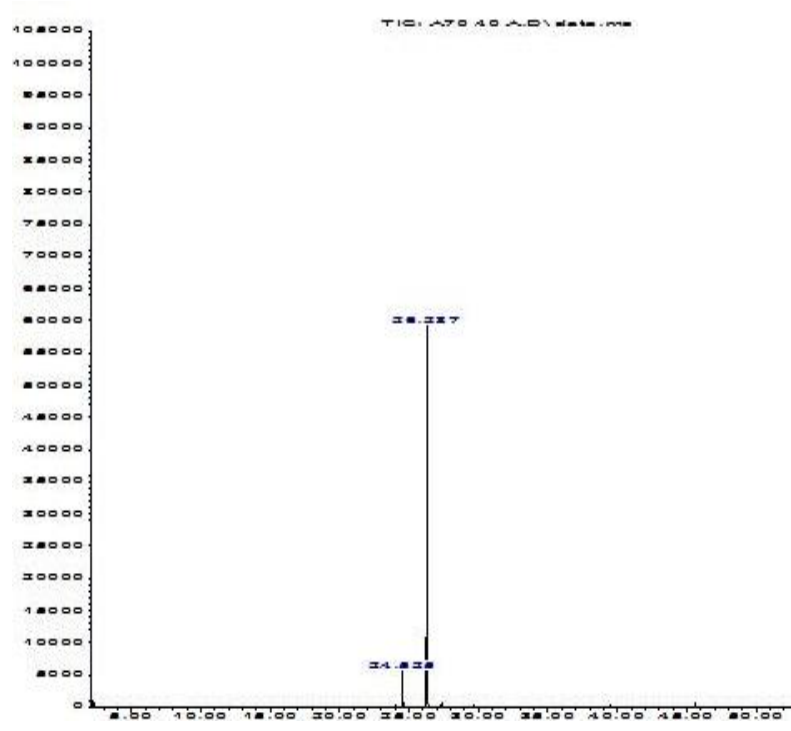

Gambar 8. Kromatogram isoeugenol hasil sonikasi menggunakan katalis $\mathrm{RhCl}_{3}$ dengan pelarut etanol pada amplitudo $70 \%$ selama 40 menit 


\section{KESIMPULAN}

Isomerisasi eugenol menjadi isoeugenol yang dilakukan menggunakan metode sonikasi telah menghasilkan metode yang paling optimal, yaitu pada kondisi amplitudo $70 \%$, waktu 40 menit, pelarut etanol, dan dengan perbandingan berat katalis $\mathrm{RhCl}_{3}$ terhadap eugenol sebesar $1: 2000$. Pada kondisi tersebut dihasilkan isoeugenol total hampir $100 \%$ dengan komposisi cis isoeugenol sekitar $8,23 \%$ dan trans isoeugenol sekitar $91,76 \%$.

\section{UCAPAN TERIMA KASIH}

Penulis mengucapkan terima kasih kepada PT. Indesso Aroma yang telah menyediakan bahan berupa eugenol dan isoeugenol untuk penelitian ini.

\section{DAFTAR PUSTAKA}

Hidayat, T., dan E. Mulyono, 2006. Konversi eugenol dari minyak daun cengkeh menjadi isoeugenol dengan pemanasan gelombang mikro. Prosiding seminar nasional himpunan kimia indonesia. 12 September 2006.

Hidayat, T., E. Mulyono, dan S. Yuliani, 2007. Pengaruh katalis rhodium dan konsentrasi pelarut etanol pada sintesis isoeugenol dari eugenol minyak daun cengkeh dengan gelombang mikro. Prosiding seminar nasional dan pameran perkembangan teknologi tanaman obat dan aromatika. Bogor, 6 September 2007.

Ingole, N.W. and S.V. Khedkar. 2012. The ultrasound reactor technology-a technology for future. International journal of advanced engineering research and studies 2:72-75.

Kadarrohman, A. 1994. Mempelajari mekanisme dan kontrol reaksi isomerisasi eugenol menjadi isoeugenol. Tesis, Program
Studi MIPA, Program Pascasarjana Universitas Gadjah Mada.

Kadarrohman, A., H. Sastrohamidjojo, dan M. Muchalal. 1999. Study of the complex reaction pathway of eugenol isomerization. Makalah Seminar Nasional Kimia Organik di Gotel Jayakarta Yogyakarta, September 1999.

Kishore, D. and S. Kannan. 2002. Isomerization of eugenol and safrole over Mg-Al Hydrotalcite, a solid base catalyst. Green Chemistry 4:607-610.

Muchalal, M. 2005. Effects of ethylene glycol and $\mathrm{KOH}$ in the formation of 2methoxy-4-propylphenol on eugenol isomerization reaction. Indo. J. Chem., 5 (1), $66-70$.

Priyosetyoko, Sudarmin, dan E. Cahyono. 2014. Transformasi eugenol menjadi isoeugenol asetat melalui isomerisasi dan asetilasi. Indo. J. Chem. Sci, 3(3): 228-232.

Roshana, A.H., S.M. Kazemzadeha, M.R. Vaezia, and A. Shokuhfar. 2011. The effect of sonication power on the sonochemical synthesis of titania nanoparticles. Journal of Ceramic Processing Research. 12 (3), pp. 299303.

Setyarini, I.S. 2010. Isomerisasi eugenol menggunakan Mg/Al-hidrotalsit dengan radiasi gelombang mikro. Skripsi Universitas Sebelas Maret, Surakarta.

Soesanto, H. 2006. Pembuatan isoeugenol dari eugenol menggunakan pemanasan gelombang mikro. Skripsi, Fakultas Teknologi Pertanian, Institut Pertanian, Bogor.

Sharma, S.K., V. K. Srivastama, and R.V. Jasra. 2006. Selective double bond isomerization of allyl phenyl ethers catalyzed by ruthenium Metal complexes. J. Mol. Catal. A-Chem, 245 200-209. 